\title{
The British Fluoridation Society
}

\section{Who founded BFS and why?}

The late, great Labour MP Dick Crossman was instrumental in the creation of The British Fluoridation Society (BFS) in 1969. As Secretary of State for Health and Social Services he could see the need for an independent organisation to communicate the benefits of water fluoridation. BFS became the scientific and academic home of this important preventive measure.

The appeal of water fluoridation to social justice campaigners is self-evident. It's a highly effective, non-invasive way to improve the life chances of children from poorer areas. Research shows on the one hand that children in more deprived families are more likely to suffer from dental caries and on the other, that fluoride strengthens tooth enamel. Although fluoride is a naturally occurring mineral, it is not universally present. Unless fluoride is introduced or topped up to the optimum level of one part per million of water, oral health inequalities are inevitable.

\section{'We carry out regular surveys of public opinion which consistently demonstrate that in England, the majority of people support fluoridation of the water. Our surveys are vital to the expert briefings we provide.'}

By the 1960s powerful evidence was in existence to support water fluoridation as a cost-effective preventive measure. The first ever fluoridation scheme had been introduced in 1945 in Grand Rapids, Michigan. Within five years, research showed that dental decay in children had reduced by $60 \%$. Meanwhile, in 1958 , three test schemes were introduced in the UK. One study compared the oral health of children in fluoridated Watford with a comparable non-fluoridated area. Speaking at a conference in 1969, Crossman described the findings of the Watford study as 'scientifically sensational', with the potential to reduce the number of fillings in children by 3.5 million annually, saving $£ 2.5$ million.

Throughout the last 75 years there has been a vocal minority opposed to water fluoridation. Emotive and scare-mongering, their faux scientific claims have the potential to whip up opposition. Water fluoridation, along with vaccinations, cloud trails and 5G masts, is a target for conspiracy theorists, hence the need for an independent organisation to ensure the scientific facts are available and accessible. The BFS is committed to providing information and articles which allow impartial observers to make up their mind based on rational argument and sound science and in the interests of children who have no voice. A healthy mouth is a lifelong advantage.

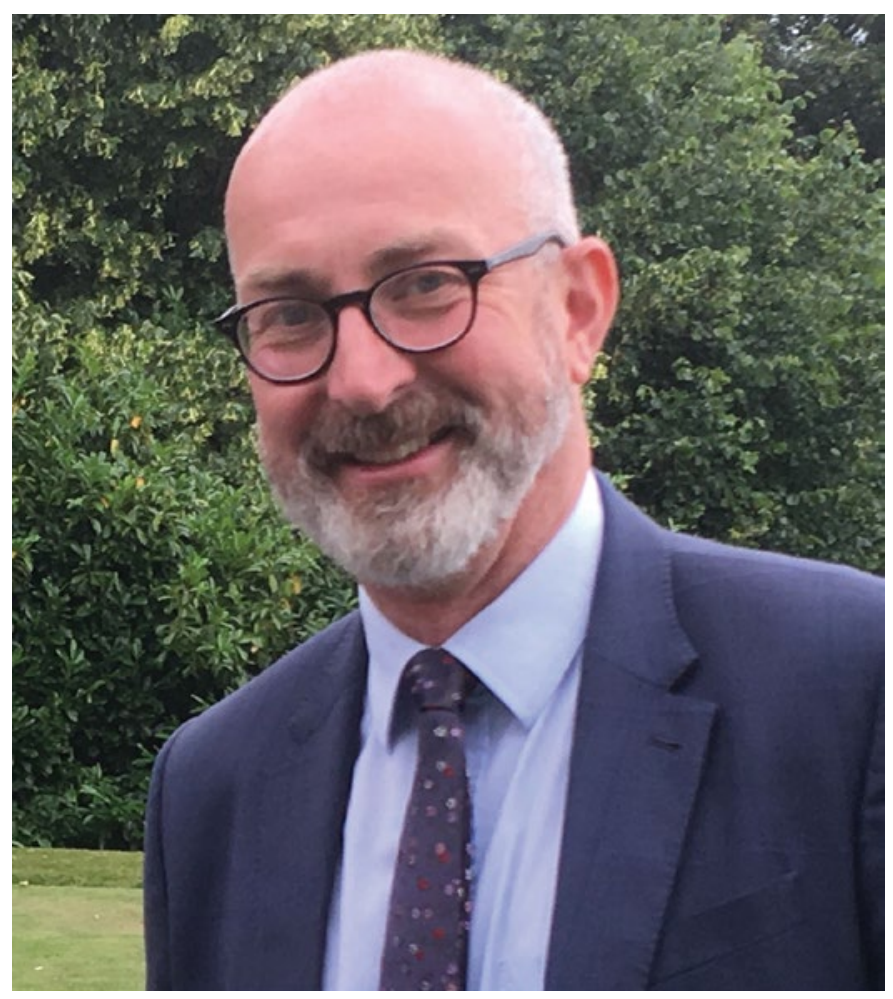

Steve Bedser, Chair of The British Fluoridation Society

\section{How do you become a member?}

The BFS is a limited company with an extensive body of worldwide followers. We have two categories of membership. Associate members have the following benefits:

- Involvement in the UK's leading water fluoridation advocacy organisation

- Access to the members area of the website

- Regular copies of the BFS Bulletin, keeping you in touch with fluoridation issues and events

- The opportunity to convert to full membership.

Full members enjoy all the above as well as a greater degree of involvement in BFS activities, including attendance at the AGM and the right to vote. We welcome both individual and corporate members who join via the website.

\section{What are the aims of the society?}

- To improve dental health through the introduction of water fluoridation schemes

- To provide professional briefings to all who need our input, whether at local, national or international level

- To support both the implementation and retention of water fluoridation schemes

- To make the BFS a self-sustaining membership organisation. 


\section{What services do you provide?}

Our key service is our formidable knowledge base built over more than 50 years which we share readily, whether with the World Health Organisation, the FDI, the NHS, the European Union, political parties, water companies, the public, researchers, public health experts, dentists and doctors, both at home and internationally. We exist to share our knowledge base with others to improve oral health and reduce inequalities.

\section{What are the society's greatest achievements?}

The history of the last 50 years has been one of positive progress followed by unlucky setbacks, due to governmental reorganisations or legislative changes. What we have achieved is all the more remarkable for being against the odds! Undoubtedly, one of our greatest achievements was to secure a change in the legislation relating to water companies. In the 1990s, several areas in the North of England were wanting to move ahead with CWF schemes. The Water (Fluoridation) Act of 1985 had made health authorities responsible for implementing schemes. But once the water companies had been privatised, they could not be mandated to comply. Pamela Taylor, CEO of Water UK, took the lead and with our support succeeded in persuading the government to amend legislation, leading to the Water Act of 2003. Water companies are now obliged to implement water fluoridation if requested by the local authority and once a public consultation has been carried out.

Another significant achievement was the successful campaign in Southampton where a judicial review found in favour of water fluoridation. Regrettably, Strategic Health Authorities were abolished by the Health and Social Care Act of 2012 which transferred responsibility for schemes to local authorities, and the opportunity for a local water fluoridation scheme was lost.

In 2012 we published the seminal One in a Million, a book which explains water fluoridation, clearly and cogently, and which we are updating. We are very proud to have inspired other organisations around the world, including the American Fluoridation Society, formed in 2014, and with whom we are fortunate to work closely.

We carry out regular surveys of public opinion which consistently demonstrate that in England, the majority of people support fluoridation of the water. Our surveys are vital to the expert briefings we provide.

Throughout the last 51 years, our council, members and allies have worked indefatigably, often behind the scenes, to help our stakeholders, wherever they may be, build a robust case for water fluoridation.

\section{What does the society hope to achieve in the next few years?}

More water fluoridation schemes in the UK and continued collaboration with similar bodies worldwide as well as at home, including the British Dental Association, the Faculty of General Dental Practitioners, the Oral Health Foundation and the CWF Network, which incorporates more than 15 professional or charitable organisations committed to water fluoridation. We have come a long way.

info@bfsweb.org

\section{BES sponsors patient information video}

As part of World Antimicrobial Awareness Week (18-24 November 2020) the British Endodontic Society (BES), along with the University of Lancaster, has sponsored a video that raises awareness of when antibiotics are not required to treat dental pain.

Overuse of antibiotics has led to the emergence of bacterial strains that are resistant to multiple groups of antibiotics. Infections with such bacteria can be fatal. Just 70 years after the introduction of antibiotics we are facing the possibility of a future without them being effective.

The idea behind the video is to mitigate patients' expectations by explaining some of the ways in which dental pain should be treated. It offers viable alternatives to antibiotics and outlines the appropriate courses of action in different situations. The overarching message is that most causes of dental pain should not be treated with antibiotics.

Phil Tomson, Hon. Secretary of the BES, said: 'The video is just one and a half minutes long and simple to follow. Its style makes it patient and family-friendly and we are very keen for it to be shared with patients and within the dental and health communities so the message reaches as many people as possible?.

The video concludes with a useful link to find out more about antibiotic resistance by visiting www.antibioticguardian.com.

The video was produced by Drs Shalini Kanagasingam (UClan), Nargis Sonde (UClan) and Phil Tomson (BES).

To view the video visit https://britishendodonticsociety.org.uk/ patient-public/use-of-antibiotics/. 